\title{
Development of equipment for jerusalem artichoke processing
}

\author{
Cassiano Rodrigues Moura, José Oliveira da Silva, Régis Kovacs Scalice \\ State University of Santa Catarina \\ e-mails: cassianocrm@hotmail.com; dep2jos@joinville.udesc.br; rkscalice@gmail.com
}

\begin{abstract}
The Jerusalem artichoke (Helianthus tuberosus Linnaeus) is a plant used as phytotherapic medicine, which is a growing segment in Brazil. Due to the demand increase, the processing method does not meet the market expectations, demonstrating the requirement for new processes and equipment. Currently small agriculturists extract the product using an artisanal method. In this paper we used a design methodology to elaborate an equipment concept to mechanize the Jerusalem artichoke processing, focusing on family farms. The project was supported by the Santa Catarina Rural Extension and Agricultural Research Enterprise (EPAGRI) which aided with mapping the process necessities. The resulting product of this work can contribute to family farming development, bringing improvements for productive process and working conditions. The product concept has modular characteristics, thus being adaptive to the needs of small producers.
\end{abstract}

Keywords: product development, family farming, agricultural mechanization, Jerusalem artichoke.

\section{Introduction}

The use of medicinal plants for treatment of diseases is increasing, according to the National Agency of Sanitary Monitoring (AGÊNCIA..., 2013) which already regulates more than 60 medicines which can be commercialized in Brazil, including the Jerusalem artichoke. These medicines, known as herbal medicines, are composed of substances used for therapeutical purposes. The Helianthus tuberosus Linnaeus is a plant belonging to Asteraceae family and is known as Jerusalem artichoke, sunroot and topinambour. The Jerusalem artichoke is being used as a phytotherapic medicine (BOTANY LESSONS, 2013). The extract of Jerusalem artichoke is produced and commercialized in Brazil, and is called dry basis of topinambour.

In the state of Santa Catarina, small producers manufacture this medicine using an artisanal method. Currently the processing of this product is unproductive and exhausting, with no specific equipment for this purpose in the market. This makes the work of small producers harder and makes the activity less profitable. It is important to highlight that the production model of small properties is predominant in the state, and despite the substantial presence of family farms, such a process cannot be characterized as subsistence agriculture.

This study originated from observation and analysis of the manufacturing process of dry basis of Jerusalem artichoke, where we identified the low productivity in the current manual process. As a result, this study has the objective to develop a concept for the equipment that would be adequate for the needs of small and medium-size producers. This equipment will provide an improvement in the productivity and in the final product quality, as well as an income increase for producers and more efficiency in the extraction process. This will only be possible through the development of specific equipment. The work was developed in collaboration with the Santa Catarina Rural Extension and Agricultural Research Enterprise (EPAGRI) who supplied information for understanding the problem.

\section{Theoretical background}

According to Pahl et al. (2007), product development is a process of analysis and subsequent process synthesis that involves stages of work and decisions, being initially qualitative and becoming increasingly concrete and quantitative. According to the author, the development conditions require three aspects of the product:

- Planning the content of the project and development process;

- Establishment of a schedule of stages of work for the project and development process;

- Plan the product costs, aiming not to exceed a predetermined limit.

Rozenfeld et al. (2006) define product development as a set of activities by which the specifications of the product design or its production process can be reached, to allow it to be manufactured. For this purpose, the necessities of the market, technological restrictions and the competitive strategies and product of the company are taken into consideration. 
Table 1 illustrates a comparative chronology of advances regarding product development. Notice the similarity between the models, particularly in the case of informational, conceptual and detail design. With this study, it is possible to identify that the main conceptual differences among the various authors are concentrated in detailing the phases.

\section{Methodology}

This paper is characterized as applied research, as it seeks product creation. In terms of goals, it can be classified as exploratory research, because it aims to understand the current problem to propose a solution (the product in this case) afterwards. The procedures include field research by monitoring the in loco activities, bibliographical research (mainly patents) to search for possible existing solutions, and surveys through interviews with EPAGRI specialists and producers from the state of Santa Catarina. The second phase was characterized by research action, where the team started to work on product conception.

The research is divided into four stages. The first stage is the problem evaluation, where a survey was carried out to study the extraction process of the Jerusalem artichoke dry basis, as well as the analysis of the product to be developed and the benefits it can achieve. The second stage covers a literature review on the process of product development by addressing different authors focusing on concepts and methods for the definition of the reference model that best address the project needs and designer preferences. From the model definition the development stage begins, when the methods and tools to create the product concept are applied. The research will be concluded in its fourth stage with an evaluation of results.

For this particular paper, it was adopted the following procedure to the product development. The planning is performed at the initial phase, within of the informational design phase, which also comprises the collection of information about the necessities of the producers. This is performed with market research using a questionnaire to interview the EPAGRI specialists and carefully chosen producers. The House of Quality form Quality Function Deployment (QFD) is used to clarify the collected needs. The specifications and goals of the product will be determined at the end of this phase.

The conceptual design is the second development phase, when the market overview obtained from the informational step is converted into attractive concepts to be selected based on technical and marketing viewpoints. The functional

Table 1. Comparison among Engineering Design methods.

\begin{tabular}{|c|c|c|c|}
\hline Ulrich; Eppinger (2004) & Pahl et al. (2007) & Rozenfeld et al. (2006) & Back et al. (2008) \\
\hline Planning & - & Project Planning & Project Planning \\
\hline \multirow{2}{*}{ Development of the concept } & Task definition & Informational design & Informational design \\
\cline { 2 - 3 } & Conceptual design & Conceptual design & Conceptual design \\
\hline System design & Embodiment design & \multirow{2}{*}{ Detail design } & Preliminary design \\
\hline Detaile design & Detail design & & Detail design \\
\hline
\end{tabular}

Source: Elaborated by the author.
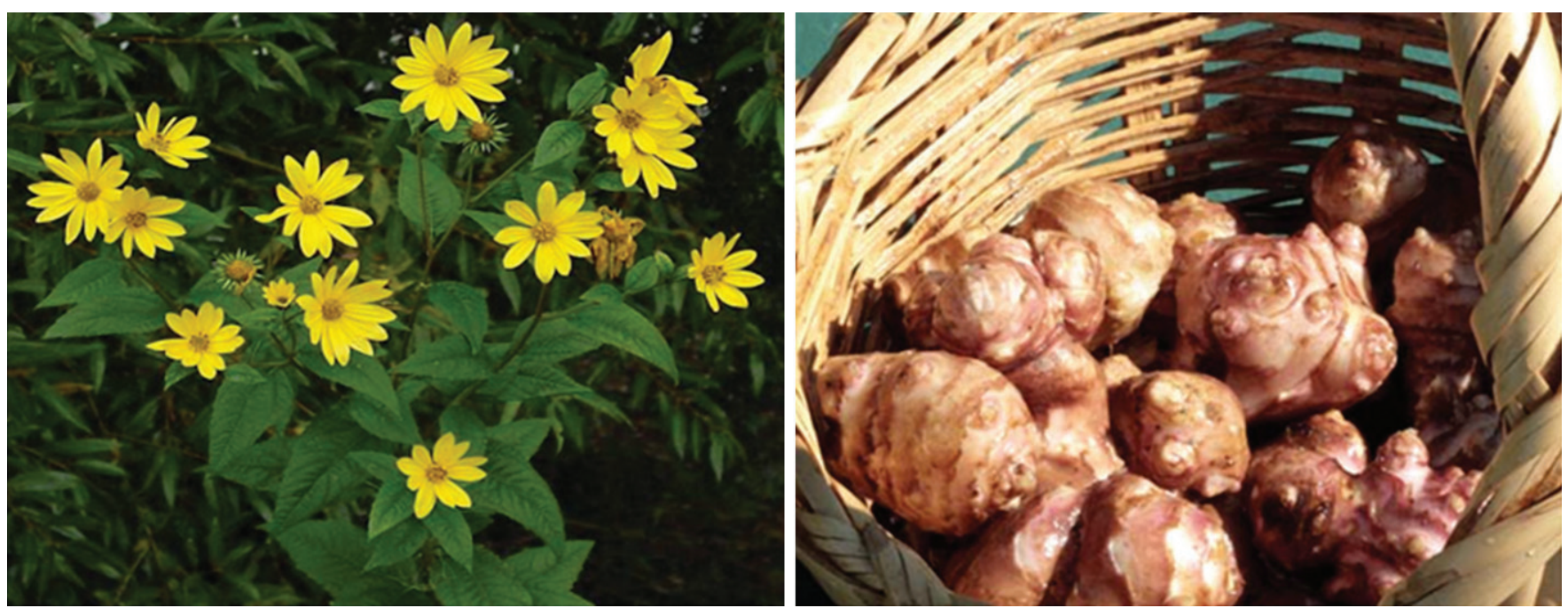

Figure 1. Jerusalem artichoke plant and rhizomes. Source: Elaborated by the author. 
modeling of the product is also performed, which results in the basis for the search for solution principles and generation of design alternatives for the product. The determination of the most proper solution will be performed by the analysis of the project technical feasibility with the aid of an evaluation matrix. To finalize the project, FMEA is employed to evaluate potential defects and failures.

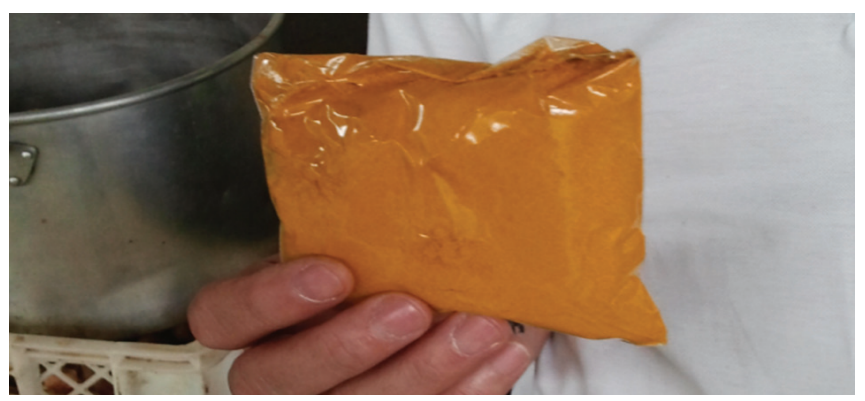

Figure 2. Jerusalem artichoke dry basis (powder). Source: Elaborated by the author.

\section{Development}

\subsection{Jerusalem artichoke production}

According to Silva Junior (2005) the Jerusalem artichoke (Helianthus tuberosus - Asteraceae), commonly known as Jerusalem artichoke, sunroot and topinambour, is native to North America. The plant forms tuberous, light yellow, irregular rhizomes with a fusiform tendency (Figure 1).

Silva Junior (2005) evidenced that the main product from the plant is the Jerusalem artichoke dry basis (Figure 2), which is considered an herbal medicine in powder form. Stored in airtight containers or bags, the powder can be added to juices, beverages, sweets, creams, ice creams and soups acting as a food supplement.

Jerusalem artichoke dry basis production in the state of Santa Catarina can be considered recent; the agriculturists that are engaged in this work are classified as small producers due to their low production capacity and artisanal extraction. Specific mechanisms for extraction of Jerusalem artichoke dry basis have not been found in the literature.

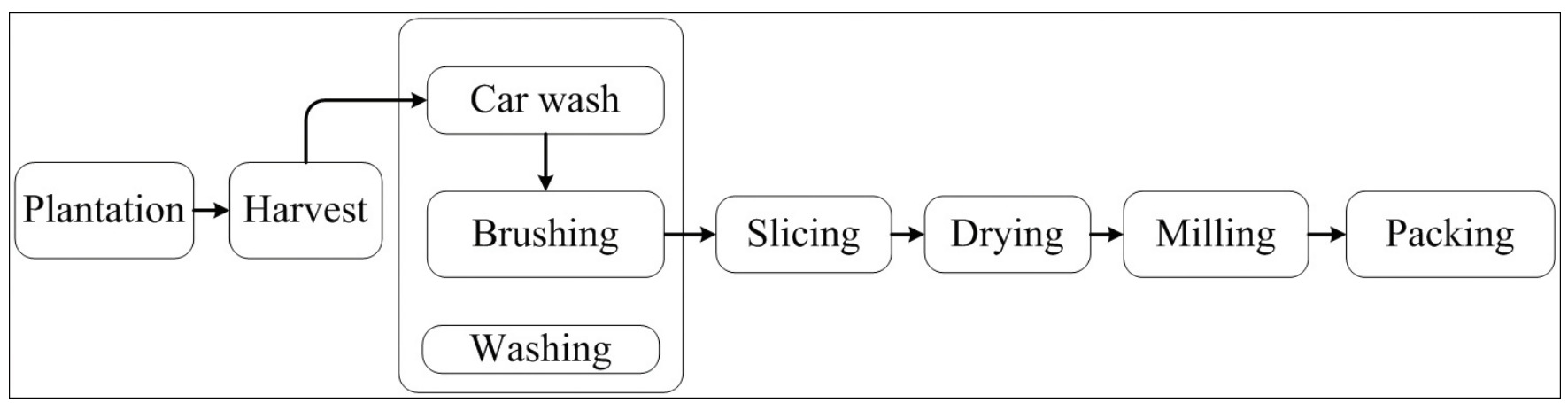

Figure 3. Jerusalem artichoke extraction process. Source: Elaborated by the author.

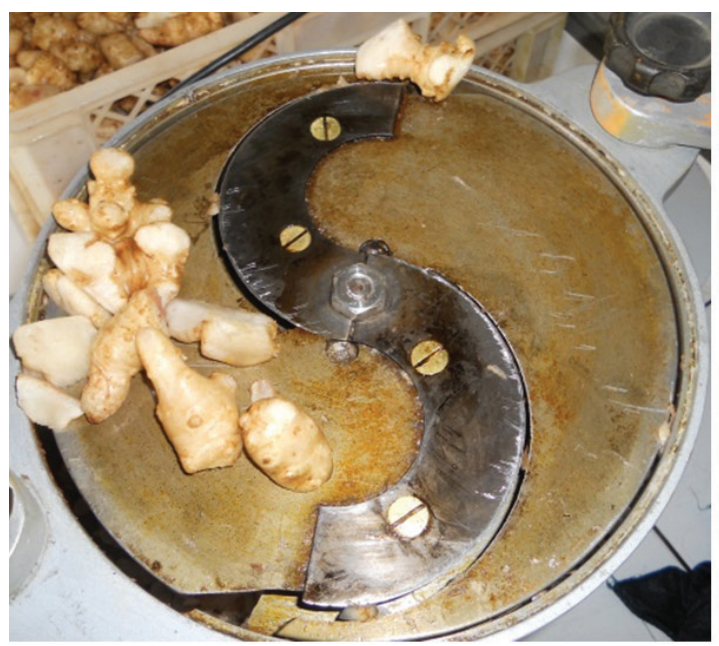

a) Slicer

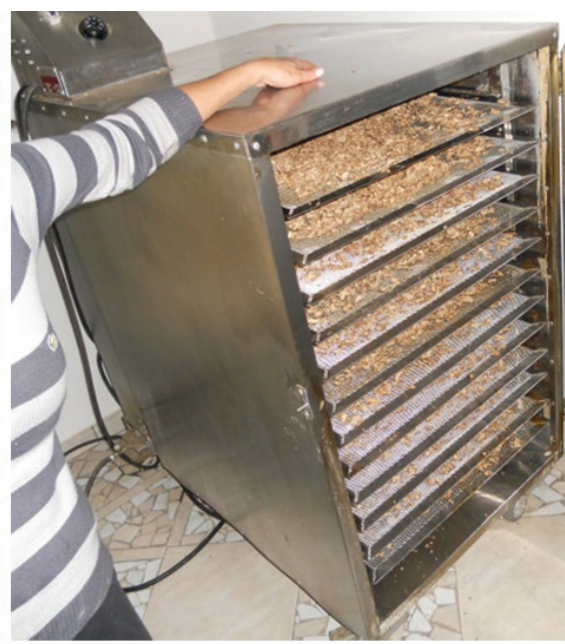

b) Oven

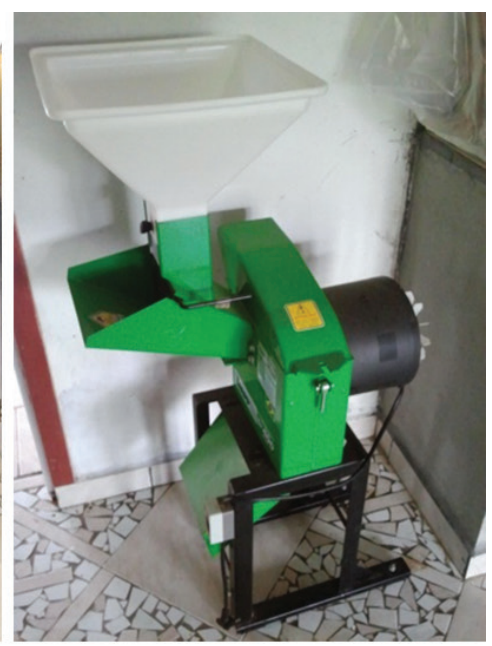

c) Crusher

Figure 4. Adapted equipment for the Jerusalem artichoke processing. Source: Elaborated by the author. 


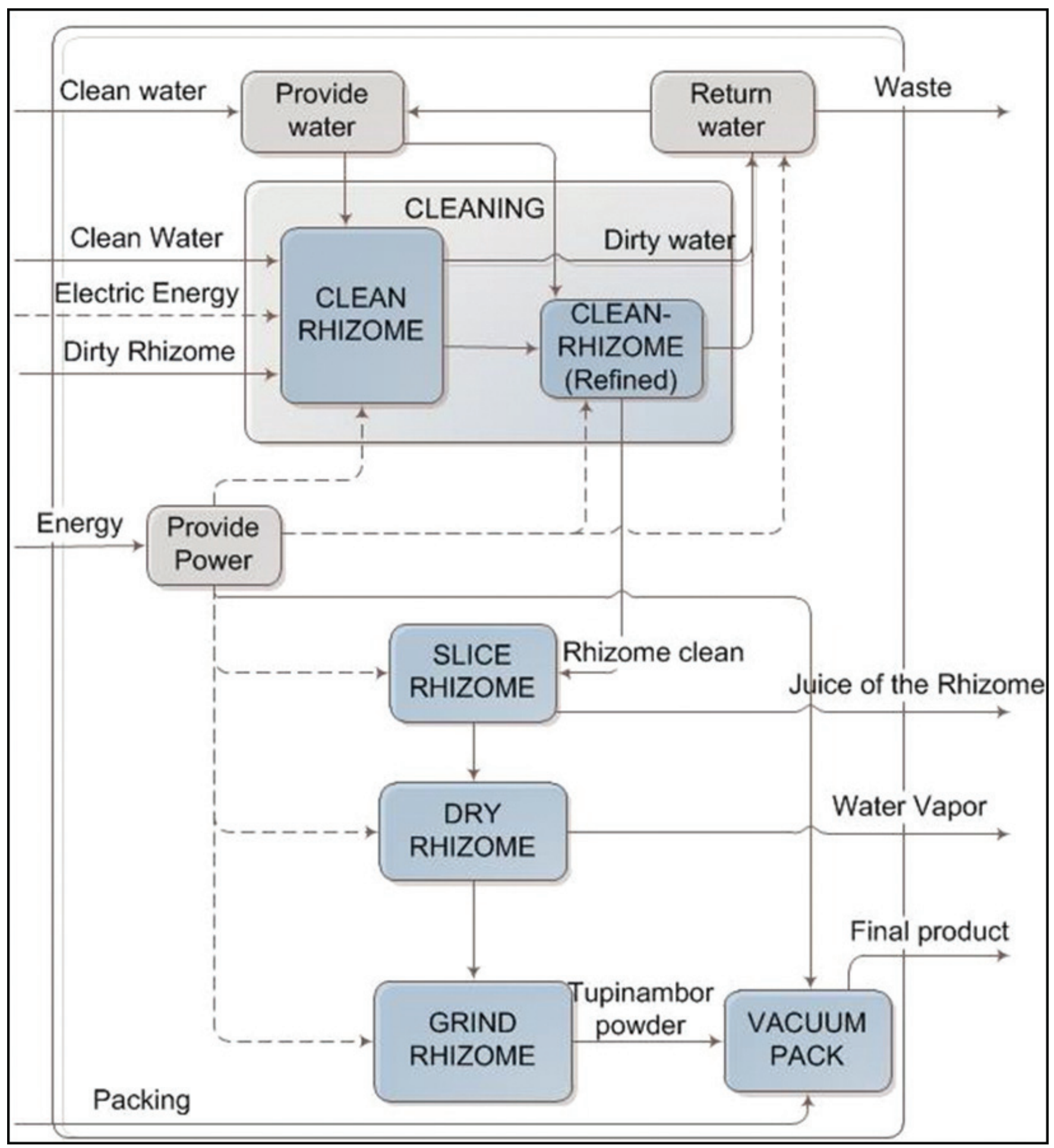

Figure 5. Overview of Process Modelling. Source: Elaborated by the author.

The current extraction process of dry basis is a slow and exhausting procedure using adapted tools from other processes, compromising the productivity. For better understanding, Figure 3 shows the extraction process flowchart of the Jerusalem artichoke dry basis.
The process flow shows that the planting and harvesting are done manually with the aid of a hoe. Subsequently, the rhizome (as seen in Figure 2) is transformed into the dry basis, starting with washing, which is divided into two steps: the use of a high pressure water jet (manual), which removes 


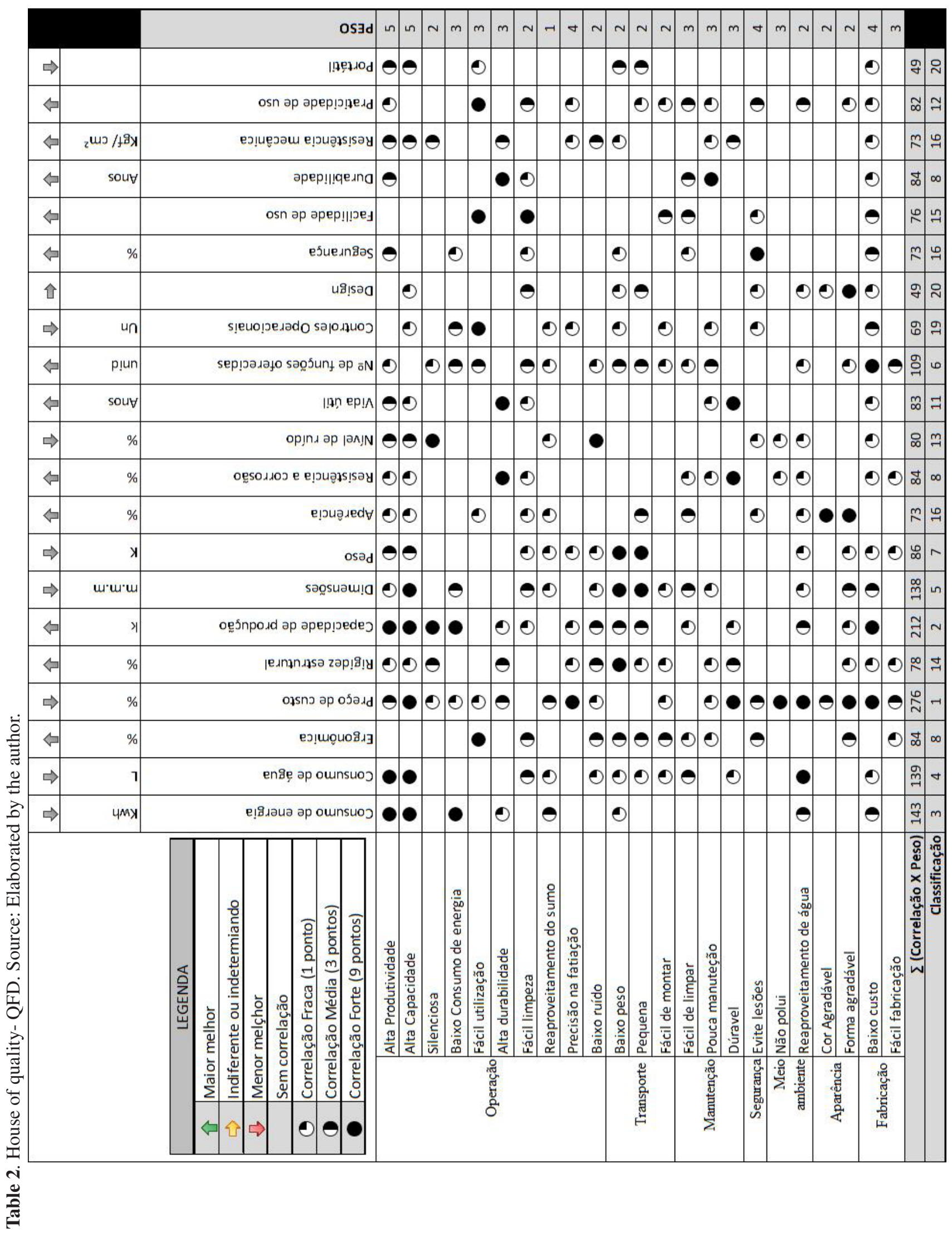


the excess dirt, and the manual brushing, which performs a refined cleaning of the rhizomes.

The first step of washing is relatively fast. However, the next phase is carried out manually with a nylon brush; each rhizome is brushed until the dirt along the sides is removed. The mechanization of this process is complicated by the fact that rhizomes have irregular shapes with different sizes.

After the cleaning process, the rhizomes go into a slicing process to standardize the size of the material. This process is performed with the use of an adapted slicing device, shown in Figure 4(a).

The drying process, illustrated in Figure 4(b) happens through an electric greenhouse, where a limitation exists because the rhizome slices have high moisture content and the drying capacity of the device is limited to approximately $10 \%$ of dry matter.

After drying, the product is ground. The grinder used in this process (Figure 4-c) is not designed specifically this purpose. As Jerusalem artichoke flour is rich in fructose, it agglomerates in the form of a mass, which locks the grinder blades, interrupting the process.

\subsection{Informational design}

This stage assesses the needs concerning extraction process mechanization of the Jerusalem artichoke dry basis in order to identify and reach the customer needs. For this stage, two producers, two technicians, an expert and an EPAGRI professional were interviewed, for a total of six subjects. The QFD correlation matrix (Table 2) lists the identified needs allowing the transformation of customer needs into design requirements. The target-specifications list is not presented due to intellectual property purposes.

\subsection{Conceptual design}

For the market overview transformation, we applied the function modelling presented in the informational design step in a technologically attractive concept according to Figure 5.

Next, we performed the assessment and generation of solution principles to satisfy the elementary functions of the functional modelling, where a morphological matrix was constructed for the modelled functions. Figure 6 illustrates part of the morphological matrix for the cleaning function.

\begin{tabular}{|c|c|c|c|c|c|c|}
\hline Function & \multicolumn{6}{|c|}{ Alternative design } \\
\hline \multirow{4}{*}{$\frac{\frac{\pi}{\mathbb{N}}}{U}$} & Car wash & Water jets & Car wash brush & Sponge & $\begin{array}{c}\text { Running water on } \\
\text { sieve }\end{array}$ & Centrifuge \\
\hline & & & & & $\$$ & \\
\hline & Vibrating table & |Hydroponics & $\begin{array}{l}\text { Water jets on } \\
\text { treadmill }\end{array}$ & $\begin{array}{c}\text { Spindle with } \\
\text { water jet }\end{array}$ & & \\
\hline & & & & & & \\
\hline \multirow{4}{*}{ 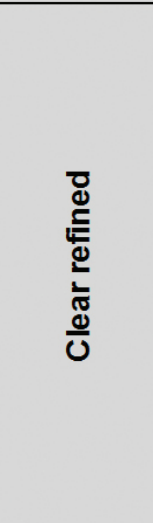 } & $\begin{array}{c}\text { Brush with water } \\
\text { jet }\end{array}$ & Steam & Jet of hot water & $\begin{array}{l}\text { Rotating drum } \\
\text { with brushes }\end{array}$ & $\begin{array}{c}\text { Barrier rotating } \\
\text { brushes }\end{array}$ & Nylon brush \\
\hline & & & (4) & & & \\
\hline & $\begin{array}{l}\text { Cylinder with air } \\
\text { vents }\end{array}$ & $\begin{array}{c}\text { Biodegradable } \\
\text { detergent }\end{array}$ & Sandblast & & & \\
\hline & & & 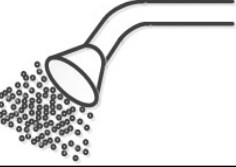 & & & \\
\hline
\end{tabular}

Figure 6. Morphological matrix. Source: Elaborated by the author. 


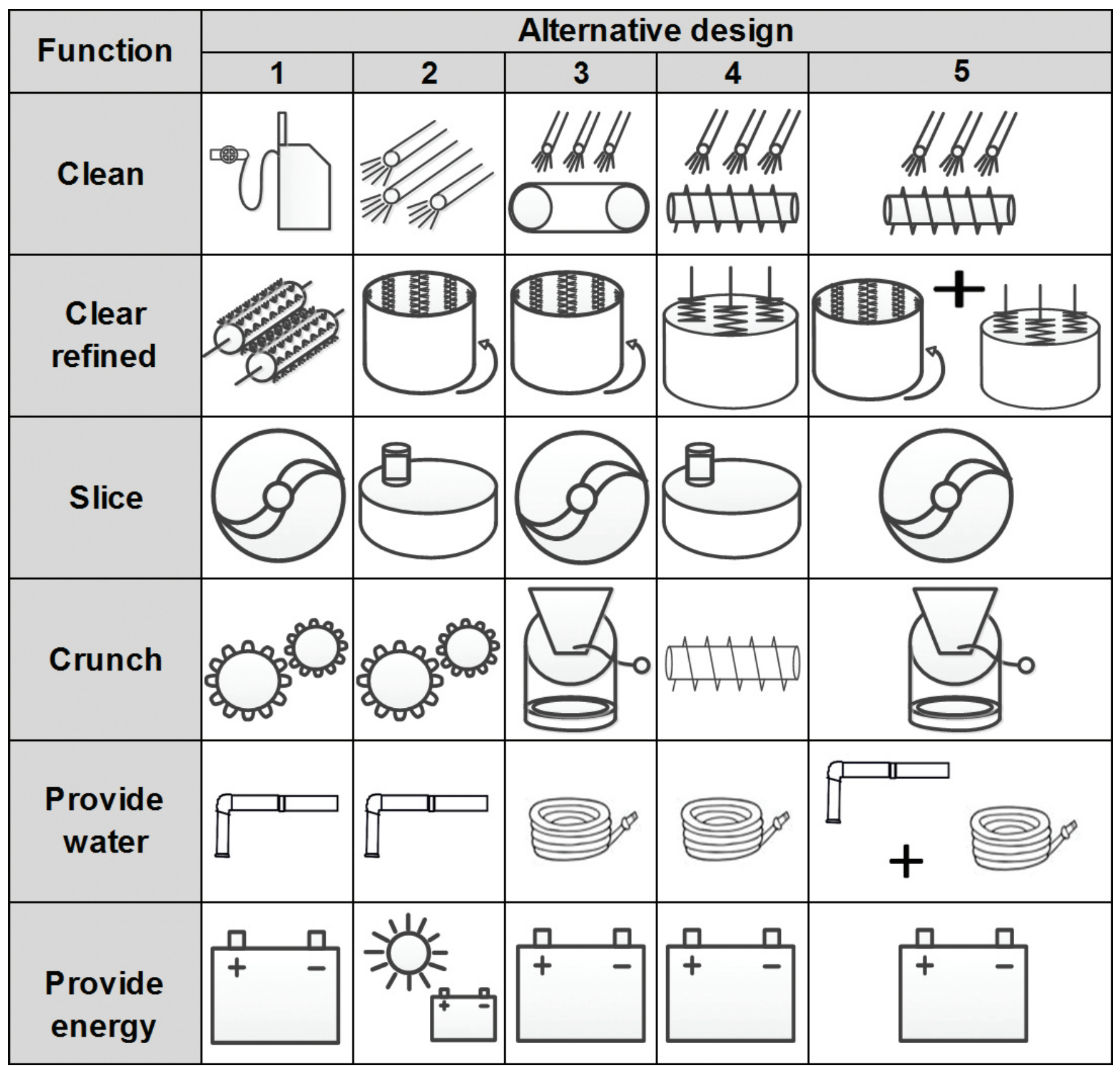

Figure 7. Alternative concept. Source: Elaborated by the author.

From the combination of the solution alternatives of the morphological matrix, we proposed the concept alternatives illustrated in Figure 7.

After the definition of the concept alternatives, we selected the most adequate one for the customer requirements. For this purpose, we use a Pugh Matrix (1991) filled by a team with the engineering knowledge of the product, which resulted in the selection of concept number 5. Thus, we decided to remove the grinding functions in the conception of this equipment, due to the existence of machines to perform this task.

\subsection{Embodiment design}

In this stage, we generated a sketch for the design alternative in CAD. Some modifications were performed based on the Failure Modes and Effect Analysis (FMEA). The first Bill-of-materials of the product was also created, which resulted in the concept presented in Figure 8. Notice 


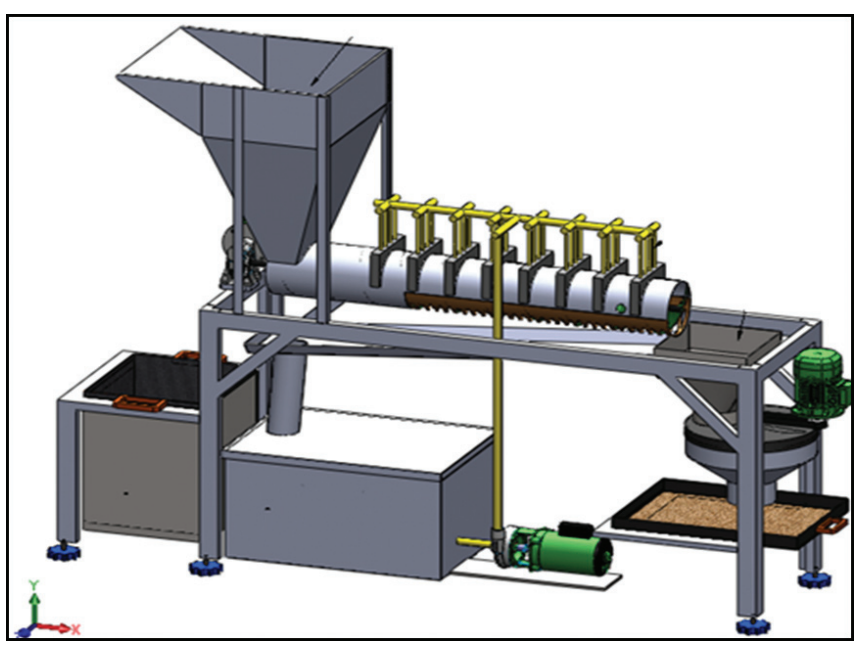

Figure 8. Illustration of the proposed concept. Source: Elaborated by the author.

the motorization and the gutter system for filtering and reuse of water in the cleaning process. This concept must be further detailed in order to be put into action, but it already has a level maturity that allows its viability and operation.

\section{Final comments}

This study used methods and tools of product development to propose a concept of appropriate equipment for the needs of small producers for the mechanization of tupinambor processing. The aim of the research was achieved with the adopted processes, and the proposed device concept has been presented and proved to be feasible for subsequent detailed projects. It is important to emphasize that this is an ongoing project, with the detail and test phases still being required to corroborate the performed preliminary analysis.

\section{References}

AGENCIA NACIONAL DE VIGILÂNCIA SANITÁRIA - ANVISA. It presents information on the organization. Available from: <http://www.portal.anvisa. gov.br>. Access in: 05 June 2013.

BOTANY LESSONS. It presents information on the organization. Available from: <http://aulasdebotanica. blogspot.com.br/2012/07/asteraceae.html>. Access in: 05 June 2013

BACK, N. et al. Projeto integrado de produtos: planejamento, concepção e modelagem. Barueri: Malone, 2008.

PAHL, G. et al. Engineering design: a systematic approach. Springer, 2007. http://dx.doi.org/10.1007/978-1-84628319-2

PUGH, S. Total design: integrated methods for successful product engineering. Addison Wesley, 1991.

ROZENFELD, H. et al. Gestão de Desenvolvimento de Produtos: Uma Referência para a Melhoria dos Processos. Saraiva, 2006.

SILVA JUNIOR, A. A. Tupínambor - fitoadaptógeno da vitalidade e longevidade. Agropecuária Catarinense, 2005.

ULRICH, K. T.; EPPINGER, S. D. Product Design and Development. Mc Graw Hill, 2004. 